\title{
An unusual illegitimate recombination occurs in the linear-plasmid-encoded outer-surface protein A gene of Borrelia afzelii
}

\author{
Jianhui Wang, Toshiyuki Masuzawa, Muqing Li \\ and Yasutake Yanagihara
}

Department of

Microbiology, School of

Pharmaceutical Sciences, University of Shizuoka, 52-1 Yada, Shizuoka 422, Japan

\author{
Author for correspondence: Jianhui Wang. Tel: +8154264 5710. Fax: +81542645715. \\ e-mail: gp1018@mail.p.u-shizuoka-ken.ac.jp
}

Keywords: illegitimate recombination, OspA variation, Borrelia afzelii, Lyme disease

\section{INTRODUCTION}

Lyme disease, a tick-borne infection causing a multisystem illness, is caused by Borrelia burgdorferi sensu stricto, Borrelia afzelii and Borrelia garinii (Burgdorfer et al., 1982; Baranton et al., 1992). All Borrelia spp. are distinguished by their characteristic morphology and motility, as well as a very high $(\geqslant 70 \mathrm{~mol} \%) \mathrm{A}+\mathrm{T}$ content in their DNA (Barbour \& Hayes, 1988). A striking peculiarity of this genus is their genome structure, consisting of linear chromosome of approximately $1000 \mathrm{~kb}$ and a series of circular and linear plasmids, some of which are thought to carry genes encoding factors that contribute to virulence (Saint Girons et al., 1992; Simpson et al., 1990). The circular and linear plasmids of the Lyme disease agents are suggested to have a common origin (Barbour et al., 1996; Dunn et al., 1994; Zückert \& Meyer, 1996), and to replicate by a shared mechanism of rolling circle (RC) replication (Ferdows et al., 1996; Marconi et al., 1996). The RC mode of replication is known to lead to high

Abbreviations: Osp, outer-surface protein; RC, rolling circle.

The GenBank/EMBLDDBJ accession numbers for the ospA sequence of $B$. afzelii strains R9 and XJ23 reported in this paper are U78549 and U78301. frequencies of both homologous recombination between long homologous sequences and illegitimate recombination between sequences of little or no homology (Michel \& Ehrlich, 1986; Niaudet et al., 1984).

Genes for the outer-surface proteins OspA and OspB are situated in a single operonic arrangement on the largest of the linear plasmids, which range in size from 48 to $60 \mathrm{~kb}$ (Bergström et al., 1989; Jonsson et al., 1992; Saint Girons et al., 1992). The OspA and OspB proteins have been suggested to play important roles in host-parasite interactions during Lyme borreliosis (Coleman et al., 1995; Comstock et al., 1993; Fikrig et al., 1992, 1994; Ma \& Weis 1993; Sadziene et al., 1993; Sellati et al., 1996) and antigenic variation of the two Osps might enable the pathogen to survive host immune attacks and establish a chronic infection (Callister et al., 1993; Fikrig et al., 1995; Marconi et al., 1993; Sadziene et al., 1992). The $\operatorname{spp} A$ and $\operatorname{csp} B$ genes exhibit a high degree of sequence similarity, and have possibly been duplicated from an ancestral osp gene. Our recent study showed that the two genes from a $B$. garinii strain shared a consensus $282 \mathrm{bp}$ sequence in their carboxyl termini (Wang et al., 1997). Homologous recombination between the ospA and ospB genes (Rosa et al., 1992) and several other variation mechanisms of OspA and OspB, including gene deletion (Marconi et al., 1993), point 


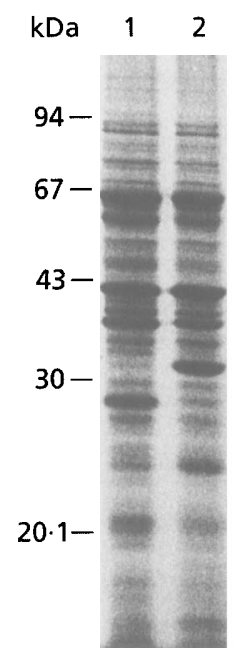

(a)

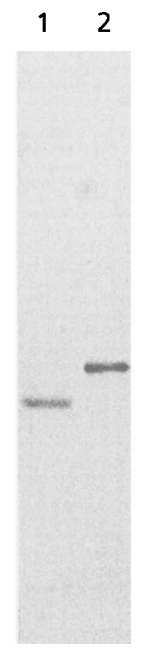

(b)

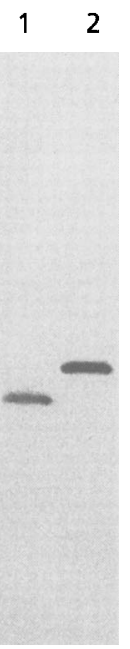

(c)
Fig. 1. SDS-PAGE and Western blotting of $B$. afzelii strains $R 9$ (lane 1) and XJ23 (lane 2). Whole-cell proteins were subjected to electrophoresis on $12.5 \%(\mathrm{w} / \mathrm{v})$ polyacrylamide gel. The gels were stained with Coomassie brilliant blue (a). Separated proteins were transferred onto PVDF membrane and allowed to react with mAbs $\mathrm{P} 31 \mathrm{c}(\mathrm{b})$ and $\mathrm{O31a}$ (b). Molecular masses are indicated on the left.

mutations (Eiffert et al., 1992; Rosa et al., 1992) and loss of the $49 \mathrm{~kb}$ linear plasmid carrying the osp $A$ and $o s p B$ gene (Hughes et al., 1993), have been explored in vitro. These findings suggest the possibility of antigenic variation during human infection. Thus, analysis of isolates from patients with long-term infection would be useful.

In this work, a mutant B. afzelii strain, R9, whose OspA was changed from 32 to $28 \mathrm{kDa}$, was isolated from a patient with chronic meningitis. Sequence analysis revealed that a $96 \mathrm{bp}$ segment was deleted from the osp $A$ structural gene, and suggested that the deletion had arisen by an unusual illegitimate recombination event, which was stimulated by an 18 bp palindromic sequence and $5 \mathrm{bp}$ short direct repeats at the termini of the deleted DNA.

\section{METHODS}

Bacterial strains, plasmid, and cultivation conditions. Lyme borrelial strains used were R9 and XJ23. Strain R9 was isolated from blood of a patient with chronic meningitis (at least 4.5 years) in Mudanjiang, China, and strain XJ23 was isolated from Ixodes persulcatus tick in Xinjiang, China. The two strains were identified as $B$. afzelii by RFLP analysis on 5S-23S rRNA intergenic spacer amplicons (Postic et al., 1994) (unpublished data). The borrelial strains were cultivated in BSKII medium at $33^{\circ} \mathrm{C}$ as described by Barbour (1984).

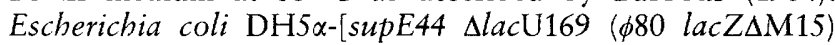
hsdR17 recA1 endA1 gyrA96 thi-1 relA1] was grown in $\mathrm{L}$ broth at $37^{\circ} \mathrm{C}$. The plasmid vector used was pUC118 (Sambrook et al., 1989). Plasmid-containing E. coli DH5 strains were grown in media supplemented with ampicillin at a final concentration of $100 \mu \mathrm{g} \mathrm{ml}^{-1}$.

SDSPAGE and Western blotting analysis. The methods employed in SDS-PAGE and Western blotting analysis were as previously described (Masuzawa et al., 1991). Ten to fifteen micrograms of bacterial protein (dry weight) was subjected to electrophoresis. The gels were stained with Coomassie brilliant blue. Separated proteins were transferred onto PVDF membranes (Millipore) by electroblotting. The mAbs used were OspA-specific mAbs P31c and O31a (Masuzawa et al., 1991).

DNA methodology. Preparation of the plasmid enrichment DNA from borrelial strains and plasmid profile analysis were performed as previously described by Barbour (1988) and Li et al. (1994). Plasmid DNA from strain R9 was partially digested with Sau3AI to generate DNA fragments, mostly in the range 2-8 kb. These DNA fragments were ligated into the Bam HI site of pUC118 with a DNA-ligating kit (Takara) and then transformed into competent $E$. coli DH5 $\alpha$ cells using a cold $\mathrm{CaCl}_{2}$ method (Sambrook et al., 1989). Using colony blotting, described below, we screened the genomic library with $\mathrm{mAb}$ P31c and selected one E. coli recombinant containing the R9 $o s p A$ gene. It was found to express a $28 \mathrm{kDa}$ OspA protein identical to the parental strain R9. The DNA fragment cloned in pUC118 was approximately $1.8 \mathrm{~kb}$. To sequence ospA, subcloning, based on convenient restriction sites, was conducted. The subclones obtained were used for DNA sequencing. Restriction endonuclease digestions and other common DNA manipulations were performed by standard procedures (Sambrook et al., 1989).

The PCR amplification was performed with a Thermo Processor model TR-100 thermal cycler (TAITEC Co.) programmed as follows: an initial denaturation step at $92^{\circ} \mathrm{C}$ for $2 \mathrm{~min}$, followed by 30 cycles consisting of $92^{\circ} \mathrm{C}$ for $1 \mathrm{~min}$, $41{ }^{\circ} \mathrm{C}$ for $30 \mathrm{~s}$, and $72{ }^{\circ} \mathrm{C}$ for $1.5 \mathrm{~min}$, with a final extension step at $72^{\circ} \mathrm{C}$ for $10 \mathrm{~min}$ to allow all extension products to be completed. A frozen Borrelia cell suspension was lysed in a boiling water bath for $10 \mathrm{~min}$ and placed immediately on ice, and then centrifuged at 2000 r.p.m. for $1 \mathrm{~min}$. The supernatant was used as PCR template. Primer A8 (5'-CAATTTTCTATTTGTTATTTGTTAATC- $3^{\prime}$ designed based on the ospA sequence of R9) annealed with 59 bp upstream from the beginning of the R9 ospA ORF and primer B9 annealed to the $3^{\prime}$ end of $\operatorname{osp} B$ (Kawabata et al., 1994) were used to amplify the strain XJ23 ospA gene.

Screening of $E$. coli recombinants by immunoblotting. E. coli recombinants were transferred from a master plate onto nitrocellulose filters and allowed to grow on the filters at $37^{\circ} \mathrm{C}$ for $15-18 \mathrm{~h}$. The recombinant colonies were lysed in a solution of $0.5 \mathrm{M} \mathrm{HCl}$ for $30 \mathrm{~min}$ and then washed with distilled water. Immunoreactivity was then examined by blotting with $\mathrm{mAb}$ P31c.

DNA sequencing. Recombinant plasmids carrying the desired inserts and freshly generated PCR products were used for DNA sequencing. The PCR products were purified with the Wizard system (Promega) and directly sequenced by the dideoxy chain-termination method with an Applied Biosystems automated sequencer (model 373A) according to the manufacturer's protocol. Primers used in sequence analysis were as follows: M13 forward primer (5'-TGTAAAACGACGGCCAGT-3') and M13 reverse primer (5'-CAGGAAACAGCTATGAC-3') purchased from Takara, and the ospA-specific primers AR1 (5'-AGCTTTTCCGGTTCCATCGC-3', nt 486-467), AF1 (5'-GAGAAAATGGAACCAAACTTG-3', nt 
416-436), AR2 (5'-ATTTCGACTGCTGTGCCTTC-3', nt 766-785) and $A 8$. The nt positions refer to the strain $\mathrm{XJ} 23$ ospA sequence.

\section{RESULTS AND DISCUSSION}

\section{OspA variation during human infection}

B. afzelii strains R9 and XJ23 were subjected to SDSPAGE and Western blotting analysis (Fig. 1). Strain $\mathrm{XJ} 23$ had a $32 \mathrm{kDa}$ OspA as B. afzelii usually expresses, but strain $\mathrm{R} 9$ expressed a $28 \mathrm{kDa}$ protein instead. The $28 \mathrm{kDa}$ protein was determined as OspA by OspAspecific mAb P31c and O31a. The OspA protein had been shown to be homogeneous including the molecular mass and $\mathrm{mAb}$ reactivities among $B$. afzelii strains isolated from various sources around the world (Masuzawa et al., 1996; Will et al., 1995). The different OspA expression of strain R9 indicated a protein variation from 32 to $28 \mathrm{kDa}$. Although strain $\mathrm{R} 9$ had a different OspA expression, it also had a plasmid content identical to that of strain XJ23 and several other strains isolated from various geographical and biological sources in China, e.g. M7 and H20 from I. persulcatus in Mudanjiang, L8 from $I$. persulcatus in Liaoning, SR1 from Rattus coxingi in Sichuan, and FP1 from patient in Sichuan (Li et al., 1994). Plasmid analysis is one of the most sensitive tools for distinguishing borrelial strains (Barbour, 1988). The identical plasmid content indicated a very close relationship between the strains. The XJ23 type strain might be the prototype form of strain $\mathrm{R9}$, or $\mathrm{R} 9$ might have been derived from the XJ23 type strain by OspA variation. Strain R9 was isolated from a chronic Lyme disease patient but not found in the environment, which may indicate that the OspA variation occurred during human infection.

\section{DNA deletion within the ospA structural gene}

To confirm the OspA variation, we cloned and sequenced the ospA gene of strain R9 and compared it to the osp $A$ sequence of strain $\mathrm{XJ} 23$ and other published data. The XJ23 ospA gene was obtained by PCR amplification with primers A8 and B9, and the PCR product was directly sequenced with primers A8, AR1, AF1 and AR2. The sequence data revealed that the R9 ospA gene has an ORF of $726 \mathrm{nt}$ encoding a putative lipoprotein of 241 aa with a calculated molecular mass of $26319 \mathrm{Da}$, and the ospA gene of strain XJ23 has an ORF with $822 \mathrm{nt}$ encoding a putative lipoprotein of 273 aa with a calculated molecular mass of $29629 \mathrm{Da}$. The XJ23 ospA sequence was almost identical to all published B. afzelii ospA gene sequences except for several base changes, e.g. it had one base change at nt 687 from $C$ to $T$ in comparison with that of strain ACA1 (Jonsson et al., 1992). Comparing the two ospA genes in Fig. 2, a DNA deletion from the R9 ospA structural gene was found. The deleted sequence was $96 \mathrm{bp}$ long from nt 142 to 237 , and the upstream and downstream sequences from the deleted DNA were almost identical to the XJ23 osp $A$ gene except for four base changes, from $\mathrm{T}$ to $\mathrm{C}$ at nt $441, A$ to $G$ at nt $543, G$ to $C$ at nt 574 , and $A$ to $G$ at nt 691. With the deletion, 32 aa were lost and the deduced molecular mass of OspA protein changed from $29629 \mathrm{Da}$ to $26319 \mathrm{Da}$.

\section{Molecular mechanism of the postulated DNA rearrangement}

To clarify the mechanism leading to the R9 ospA recombination, attention was focused on the nature of the deleted DNA and the sequences flanking the recombination sites. The deletion occurred at positions nt $141 / 142$ and nt $237 / 238$. Beginning at position nt 136 were a pair of 6-mer direct repeats (AAAGAC) in tandem, and following and overlapping it by four bases (AGAC), was an 18-mer inverted and complementary repeat (AGACGGTAAGTACAGTCT) at nt 144-161. Furthermore, a 5-mer short direct repeat (AAAGA) was found at both termini of the deleted DNA (nt 142-146 and nt 238-242). These findings suggested a possibility of an illegitimate recombination event.

Illegitimate recombination has two different mechanisms: (i) end-joining, mediated by enzymes which cut and join DNA, such as topoisomerases, site-specific DNases and proteins which initiate $\mathrm{RC}$ replication, and involve sequences which include or resemble those on which such enzymes normally act; (ii) strand slippage, where, after pausing at the replication fork, the nascent strand is able to dissociate from one template and pair with another (Ehrlich et al., 1993; Pinder et al., 1997). About half of the reported illegitimate recombination events involve short homologous sequences, its key feature being slippage of the tip of a growing DNA chain from one repeat to the other (Ehrlich et al., 1993). No special motif recognized by specific cut-and-join enzymes could be identified in the sequence, indicating that the deletion event may have arisen by a strand slippage mechanism. Using a computer program (Genetyx-MAC/ATSQ Automatic connection of sequences, version 8.0; Software Developments), we analysed the structure of the deleted DNA by searching for hairpins, palindromes and secondary structures, and propose a model to explain the rearrangement in the osp A gene (Fig. 3). Sequences which have the potential to form unusual secondary structures (e.g. palindromes, which can form hairpins when single-stranded, or cruciforms when double-stranded) are known to promote pausing of DNA replication and stimulate replication slippage (Michel \& Ehrlich, 1986; Ehrlich et al., 1993). Long DNA palindromes are unstable in both eukaryotes (Collick et al., 1996) and prokaryotes (Peeters et al., 1988; Weston-Hafer \& Berg, 1989, 1991) and have been shown to halt the progress of the replication fork in vitro (LaDuca et al., 1983; Bedinger et al., 1989).

As shown in Fig. 3, we suggest that the first step is the rare extrusion of the inverted sequences to form an unstable cruciform by intrastrand base pairing, which causes the DNA polymerase to pause. Many studies of 


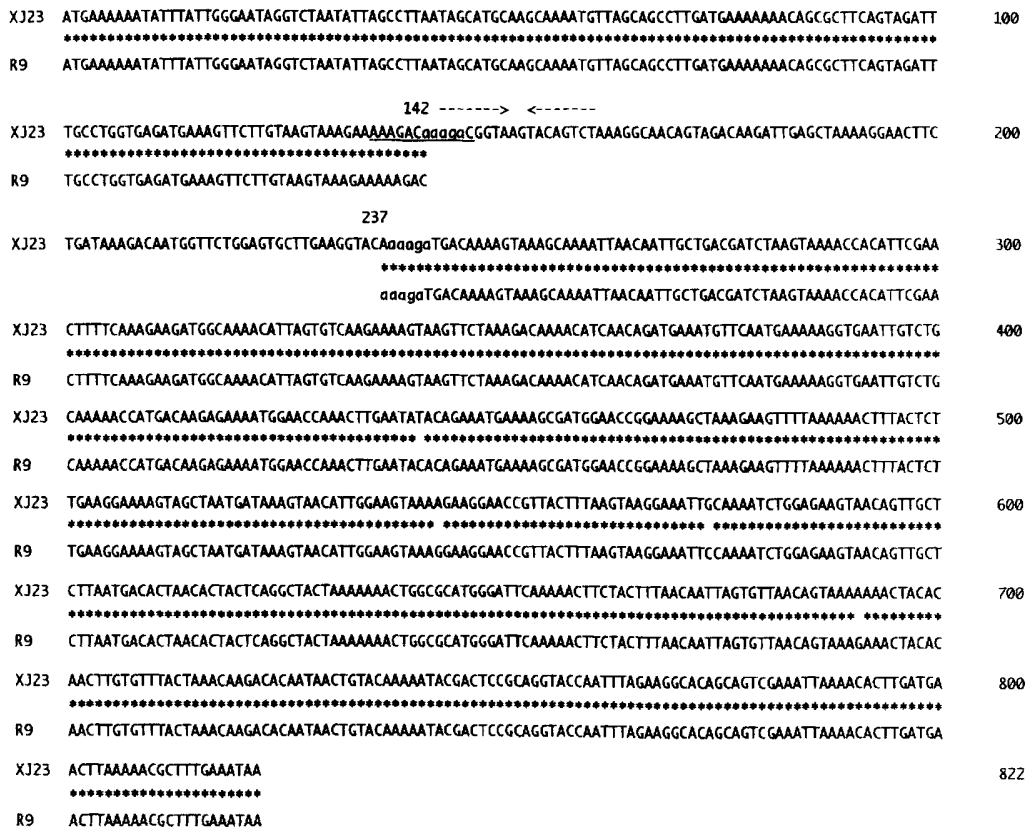

Fig. 2. Comparison of the ospA genes of $B$. afzelii strains R9 and XJ23. A 96 bp-long DNA deletion from the R9 ospA gene was found at nt 142-237; the upstream and downstream sequences flanking the deleted DNA were almost identical to that of XJ23 except four bases changed from $T$ to $C$ at nt $441, A$ to $G$ at $n t 543, G$ to $C$ at $n t 574$, and $A$ to $G$ at nt 691 . The pair of 6-mer direct repeats (AAAGAC) in tandem at nt 136-147 is underlined, and overlapping it by four bases an 18-mer inverted and complementary repeat is indicated by broken arrows at nt 144-161. In addition, a 5-mer aaaga indicated by small characters was found at the beginning of the deleted DNA (nt 142-146) and just following the deleted DNA (nt 238-242).

deletions stimulated by palindromic sequences have shown that deletion end points tend to occur in short direct repeats, and that DNA rearrangement by strand slippage leads to deletion of one of the repeats and the palindromic sequences between the repeats (Ehrlich et al., 1993; Pinder et al., 1997). The recombination event presented did not seem to follow this rule. Although there were imperfect short direct repeats (AAAGC at nt 142-146, and AAAGG at nt 162-166) flanking the $18 \mathrm{bp}$ palindromic structure, the recombination did not occur between them. Instead of that, it occurred with another direct repeat (AAAGC at nt 238-242) 76 bp downstream from the $18 \mathrm{bp}$ palindrome. The unusual recombination could be explained by strand separation and formation of a hairpin complex. The low $\mathrm{G}+\mathrm{C}$ content of Borrelia genomic DNA might help the formation of the unusual secondary structure. The hairpin loop was considered to form after cruciform formation because this might cause pausing of DNA replication. However, if the laggingstrand synthesis in RC replication is slow and/or initiated relatively infrequently along the newly synthesized rolling strand, the hairpin loop formation could occur without prior cruciform formation. The formation of the hairpin complex may have brought the short direct repeats closer together and facilitated replication across the fork from the leading to the lagging strand by base-pairing between the two short direct repeats. Three direct repeats (AAAGAA/AAAGAC/AAAGAC nt 130-146) in tandem at the upstream site of the deletion appeared to play a key role in the nascent strand slippage across the replication fork. After the strand slippage, further DNA synthesis led to loss of the hairpin complex and one of the short direct repeats.

\section{OspA variation and pathogenicity}

It is not clear how important this type of strand slippage event has been in genome evolution. Monoclonal or polyclonal antibodies to OspA or OspB have been shown to have roles in the selection of variant spirochaetes in vitro (Sadziene et al., 1992) and in vivo (Fikrig et al., 1995). Although without direct evidence, strain R9 had been immediately analysed by SDS-PAGE and found to express a variant OspA when it was isolated from the patient (Li et al., 1994), and this kind of mutant was never isolated from the environment, whereas Borrelia strains with a complete ospA gene were generally isolated from various sources (Will et al., 1995), suggesting that the OspA variation of strain R9 may have occurred during human infection and the mutant strain may have been selected by human immune pressure. All ospA genes of the three Lyme disease Borrelia species (B. burgdorferi s. s., B. afzelii and $B$. garinii) were shown to have sequence conservation within the $\mathrm{N}$ terminus (Will et al., 1995). This implied that the slippage model could in theory be used by Lyme borrelial strains. However, the findings that strain FP1, 
Prototype ospA gene
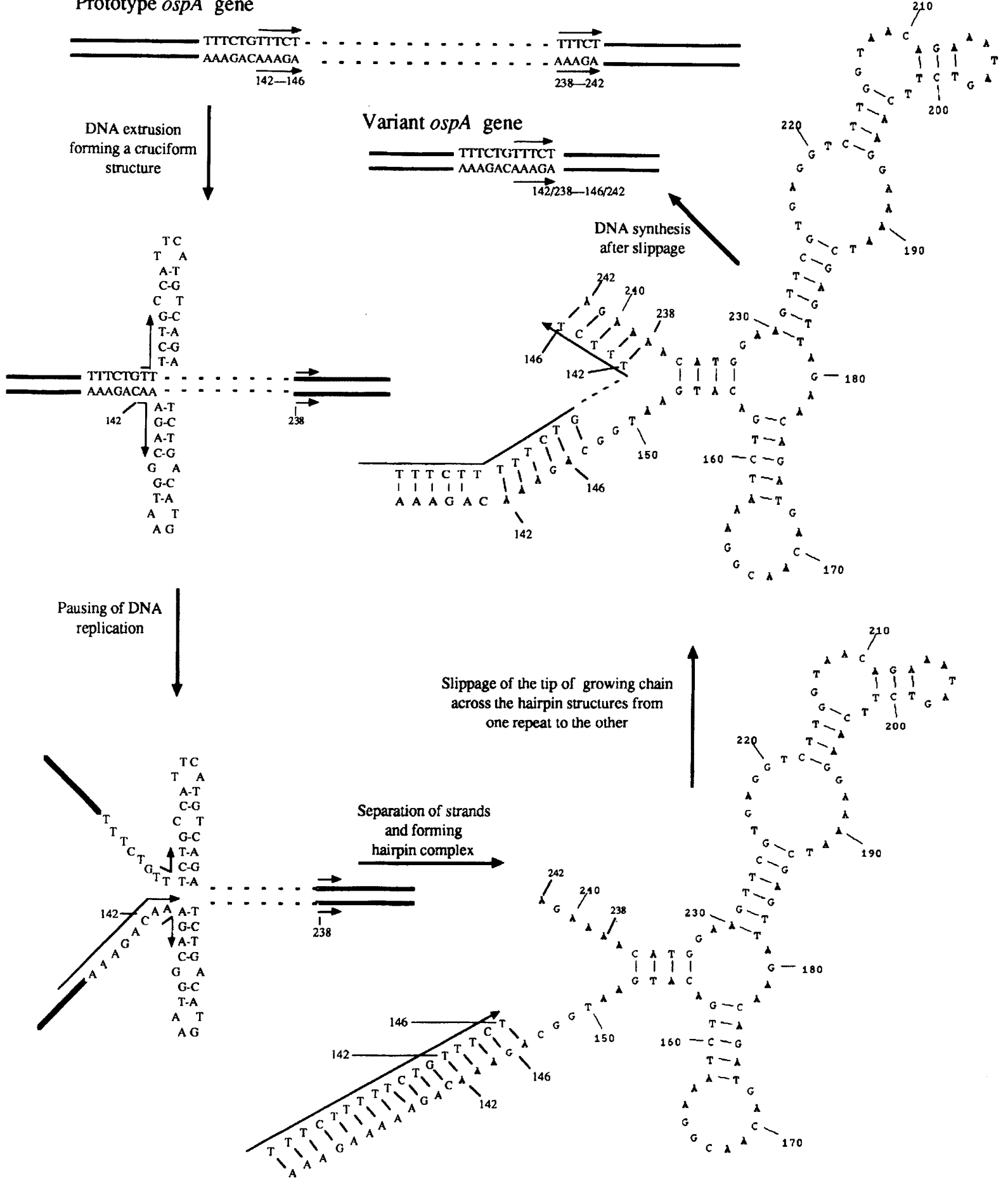

Fig. 3. Model of the DNA rearrangement by strand slippage mechanism. The deleted DNA is indicated by a broken line and the sequences flanking the deleted DNA are indicated by a thick line. The short direct repeats at both termini of the deletion are shown and indicated by short arrows, and the growing chain is represented by a long thin arrow. See text for further details.

which had similar features to strain XJ23 (Li et al., 1994), and other strains (Will et al., 1995) isolated from Lyme disease patients, had no OspA or OspB changes, and that Borrelia OspA was stable in the re-isolated strains from chronically infected immunocompetent mice (Persing et al., 1994), indicate that the rearrangement in the R9 ospA gene was not a universal avoidance mechanism. 


\section{ACKNOWLEDGEMENTS}

This work was supported in part by a Grant-in-Aid for Encouragement of Young Scientists no. 06772143, for Scientific Research no. 07670320 and 08670312, and for International Cooperative Research: Joint Research no. 06044191, 08044310 and 08041181 from the Ministry of Education, Science and Culture of Japan.

\section{REFERENCES}

Baranton, G., Postic, D., Girons, I. Saint, Boerlin, P., Piffaretti, J. C., Assous, M. \& Grimont, P. A. D. (1992). Delineation of Borrelia burgdorferi sensu stricto, Borrelia garinii sp. nov., and group VS461 associated with Lyme borreliosis. Int J Syst Bacteriol 47, 378-383.

Barbour, A. G. (1984). Isolation and cultivation of Lyme disease spirochetes. Yale J Biol Med 57, 521-525.

Barbour, A. G. (1988). Plasmid analysis of Borrelia burgdorferi, the Lyme diseases agent. J Clin Microbiol 26, 475-478.

Barbour, A. G. \& Hayes, S. F. (1988). Biology of Borrelia species. Microbiol Rev 50, 381-400.

Barbour, A. G., Carter, C. J., Bundoc, V. \& Hinnebusch, J. (1996). The nucleotide sequence of a linear plasmid of Borrelia burgdorferi reveals similarities to those of circular plasmids of other prokaryotes. J Bacteriol 178, 6635-6639.

Bedinger, P., Munn, M. \& Alberts, B. M. (1989). Sequence-specific pausing during in vitro DNA replication on double-stranded DNA templates. $J$ Biol Chem 264, 16880-16886.

Bergström, S., Bundoc, V. G. \& Barbour, A. G. (1989). Molecular analysis of linear plasmid-encoded major surface proteins, OspA and $\mathrm{OspB}$, of the Lyme disease spirochaete Borrelia burgdorferi. Mol Microbiol 3, 479-486.

Burgdorfer, W., Barbour, A. G., Hayes, S. F., Benach, J. L., Grunwald, E. \& Davis, J. P. (1982). Lyme disease - a tick borne spirochetosis? Science 216, 1317-1319.

Callister, S. M., Schell, R. F., Case, K. L., Lovrich, S. D. \& Day, S. P. (1993). Characterization of the borreliacidal antibody response to Borrelia burgdorferi in humans: a serodiagnostic test. J Infect Dis $167,158-164$.

Coleman, J. L., Sellati, T. J., Testa, J. E., Kew, R. R., Furie, M. B. \& Benach, J. L. (1995). Borrelia burgdorferi binds plasminogen, resulting in enhanced penetration of endothelial monolayers. Infect Immun 63, 2478-2484.

Collick, A., Drew, J., Penberth, J., Bois, P., Luckett, J., Scaerou, F., Jeffreys, A. \& Reik, W. (1996). Instability of long inverted repeats within mouse transgenes. EMBO J 15, 1163-1171.

Comstock, L. E., Fikrig, E., Shoberg, R. J., Flavell, R. A. \& Thomas, D. D. (1993). A monoclonal antibody to OspA inhibits association of Borrelia burgdorferi with human endothelial cells. Infect Immun 61, 423-431.

Dunn, J. J., Buchstein, S. R., Butler, L. L., Fisenne, S., Polin, D. S., Lade, B. N. \& Luft, B. J. (1994). Complete nucleotide sequence of a circular plasmid from the Lyme disease spirochete, Borrelia burgdorferi. J Bacteriol 176, 2706-2717.

Ehrlich, S. D., Bierne, H., d'Alencon, E., Vilette, D., Petranovic, M., Noirot, P. \& Michel, B. (1993). Mechanisms of illegitimate recombination. Gene $135,161-166$.

Eiffert, H., Ohlenbusch, A., Fehling, W., Lotter, H. \& Thomssen, R. (1992). Nucleotide sequence of the $\operatorname{ssp} A B$ operon of a Borrelia burgdorferi strain expressing OspA but not OspB. Infect Immun 60, $1864-1868$.

Ferdows, M. S., Serwer, P., Griess, G. A., Norris, S. J. \& Barbour,
A. G. (1996). Conversion of a linear to a circular plasmid in the relapsing fever agent Borrelia hermsii. J Bacteriol 178, 793-800.

Fikrig, E., Barthold, S. W., Marcantonio, N., Deponte, K., Kantor, F. S. \& Flavell, R. A. (1992). Roles of OspA, OspB, and flagellin in protective immunity to Lyme borreliosis in laboratory mice. Infect Immun 60, 657-661.

Fikrig, E., Tao, H., Barthold, S. W. \& Flavell, R. A. (1995). Selection of variant Borrelia burgdorferi isolates from mice immunized with outer surface protein A or B. Infect Immun 63, 1658-1662.

Fuchs, H., Wallich, R., Simon, M. M. \& Kramer, M. D. (1994). The outer surface protein A of the spirochete Borrelia burgdorferi is a plasmin(ogen) receptor. Proc Natl Acad SciUSA 91, 12594-12598.

Hughes, C. A. N., Engstrom, S. M., Coleman, L. A., Kodner, C. B. \& Johnson, R. C. (1993). Protective immunity is induced by a Borrelia burgdorferi mutant that lacks OspA and OspB. Infect Immun 61, 5115-5122.

Jonsson, M., Noppa, L., Barbour, A. G. \& Bergström, S. (1992). Heterogeneity of outer membrane proteins in Borrelia burgdorferi: comparison of osp operons of three isolates of different geographic origins. Infect Immun 60, 1845-1853.

Kawabata, H., Tashibu, H., Yamada, K., Masuzawa, T. \& Yanagihara, Y. (1994). Polymerase chain reaction analysis of Borrelia species isolated in Japan. Microbiol Immunol 38, 591-598.

LaDuca, R. J., Fay, P. J., Chuang, C., McHenry, C. S. \& Bambara, R. A. (1983). Site-specific pausing of deoxyribonucleic acid synthesis catalyzed by forms of Escherichia coli DNA polymerase III. Biochemistry 22, 5177-5188.

Li, M. Q., Wang, J. H. \& Zhang, Z. F. (1994). Phenotypic and genotypic analysis of Chinese Borrelia burgdorferi isolates from various sources. In Lyme Borreliosis, pp. 217-225. Edited by J. S. Axford \& D. H. E. Rees. New York \& London: Plenum.

Ma, Y. \& Weis, J. J. (1993). Borrelia burgdorferi outer surface lipoproteins OspA and OspB possess B-cell mitogenic and cytokine-stimulatory properties. Infect Immun 61, 3843-3853.

Marconi, R., Casjens, S., Munderloh, U. G. \& Samuels, D. S. (1996). Analysis of linear plasmid dimers in Borrelia burgdorferi sensu lato isolates: implications concerning the potential mechanism of linear plasmid replication. J Bacteriol 178, 3357-3361.

Marconi, R. T., Konkel, M. E. \& Garon, C. F. (1993). Variability of osp genes and gene products among species of Lyme disease spirochetes. Infect Immun 61, 2611-2617.

Masuzawa, T., Okada, Y., Yanagihara, Y. \& Sato, N. (1991). Antigenic properties of Borrelia burgdorferi isolated from Ixodes ovatus and Ixodes persulcatus in Hokkaido, Japan. J Clin Microbiol 29, 1568-1573.

Masuzawa, T., Wilske, B., Komikado, T. \& 9 other authors (1996). Comparison of OspA serotypes for Borrelia burgdorferi sensu lato from Japan, Europe and North America. Microbiol Immunol 40, 539-545.

Michel, B. \& Ehrlich, S. (1986). Illegitimate recombination occurs between the replication origin of plasmid pC194 and a progressing replication fork. EMBO J 5, 3691-3696.

Niaudet, B., Jannière, L. \& Ehrlich, S. (1984). Recombination between repeated DNA sequences occurs more often in plasmids than in the chromosome of Bacillus subtilis. Mol Gen Genet 197, $46-54$.

Peeters, B. P. H., de Boer, J. H., Bron, S. \& Venema, G. (1988). Structural plasmid instability in Bacillus subtilis: effect of the direct and inverted repeats. Mol Gen Genet 212, 450-458.

Persing, D. H., Mathiesen, D., Podzorski, D. \& Barthold, S. W. (1994). Genetic stability of Borrelia burgdorferi recovered from 
chronically infected immunocompetent mice. Infect Immun 62, 3521-3527.

Pinder, D. J., Blake, C. E. \& Leach, R. F. (1997). DIR: a novel DNA rearrangement associated with inverted repeats. Nucleic Acids Res 25, 523-529.

Postic, D., Assous, M. V., Grimont, P. A. D. \& Baranton, G. (1994). Diversity of Borrelia burgdorferi sensu lato evidenced by restriction fragment length polymorphism of $r f$ (5S)-rrl (23S) intergenic spacer amplicons. Int J Syst Bacteriol 44, 743-752.

Rosa, P. A., Schwan, T. \& Hogan, D. (1992). Recombination between genes encoding major outer surface proteins $A$ and $B$ of Borrelia burgdorferi. Mol Microbiol 6, 3031-3040.

Sadziene, A., Rosa, P. A., Thompson, P. A., Hogan, D. M. \& Barbour, A. G. (1992). Antibody-resistant mutants of Borrelia burgdorferi: in vitro selection and characterization. J Exp Med 176, 799-809.

Sadziene, A., Barbour, A. G., Rosa, P. A. \& Thomas, D. D. (1993). An OspB mutant of Borrelia burgdorferi has reduced invasiveness in vitro and reduced infectivity in vivo. Infect Immun 61, 3590-3596.

Saint Girons, I., Norris, S. J., Göbel, U., Meyer, J., Walker, E. M. \& Zuerner, R. (1992). Genome structure of spirochetes. Res Microbiol 143, 615-621.

Sambrook, J., Fritsch, E. F. \& Maniatis, T. (1989). Molecular Cloning: a Laboratory Manual, 2nd edn. Cold Spring Harbor, NY: Cold Spring Harbor Laboratory.

Sellati, T. J., Abrescia, L. D., Radolf, J. D. \& Furie, M. B. (1996).
Outer surface lipoproteins of Borrelia burgdorferi activate vascular endothelium in vitro. Infect Immun 64, 3180-3187.

Simpson, W. J., Garon, C. F. \& Schwan, T. G. (1990). Analysis of supercoiled circular plasmids in infectious and non-infectious Borrelia burgdorferi. Microb Pathog 8, 109-118.

Wang, J. H., Masuzawa, T., Komikado, T. \& Yanagihara, Y. (1997). Consensus sequence on the genes encoding the major outer surface proteins (OspA and OspB) of Borrelia garinii isolate. Microbiol Immunol 41, 83-91.

Weston-Hafer, K. \& Berg, D. E. (1989). Palindromy and the location of deletion endpoints in Escherichia coli. Genetics 121, 651-658.

Weston-Hafer, K. \& Berg, D. E. (1991). Deletions in plasmid pBR322: replication slippage involving leading and lagging strands. Genetics 127, 649-655.

Will, G., Jauris-Heipke, S., Schwab, E., Busch, U., Rößler, D., Soutschek, E., Wilske, B. \& Preac-Mursic, V. (1995). Sequence analysis of ospA genes shows homogeneity within Borrelia burgdorferi sensu stricto and Borrelia afzelii strains but reveals major subgroups within the Borrelia garinii species. Med Microbiol Immunol 184, 73-80.

Zückert, W. R. \& Meyer, J. (1996). Circular and linear plasmids of Lyme disease spirochetes have extensive homology: characterization of a repeated DNA element. J Bacteriol 178, 2287-2298.

Received 14 March 1997; revised 23 June 1997; accepted 21 August 1997. 